\title{
Corrosion Reliability of Electronic Systems
}

\author{
Ambat, Rajan; Jensen, Stine G.; Møller, Per
}

Published in:

E C S Transactions

Link to article, DOI:

10.1149/1.2900650

Publication date:

2008

Document Version

Publisher's PDF, also known as Version of record

Link back to DTU Orbit

Citation (APA):

Ambat, R., Jensen, S. G., \& Møller, P. (2008). Corrosion Reliability of Electronic Systems. E C S Transactions, 6(24), 17-28. https://doi.org/10.1149/1.2900650

\section{General rights}

Copyright and moral rights for the publications made accessible in the public portal are retained by the authors and/or other copyright owners and it is a condition of accessing publications that users recognise and abide by the legal requirements associated with these rights.

- Users may download and print one copy of any publication from the public portal for the purpose of private study or research.

- You may not further distribute the material or use it for any profit-making activity or commercial gain

- You may freely distribute the URL identifying the publication in the public portal

If you believe that this document breaches copyright please contact us providing details, and we will remove access to the work immediately and investigate your claim 


\title{
CORROSION RELIABILITY OF ELECTRONIC SYSTEMS
}

\author{
Rajan Ambat, Stine Garder Jensen, and Per Møller \\ Division of Materials Science and Engineering \\ Department of Manufacturing and Management \\ Technical University of Denmark \\ DK 2800 Kgs. Lyngby, Denmark
}

\begin{abstract}
Inherently two factors namely multi-material usage and potential bias makes electronic devices susceptible to corrosion if exposed to humid conditions. The problem is compounded today due to miniaturization and contamination effects. The reduction in size of the components and close spacing on a Printed Circuit Board (PCB) for high density packing has greatly increased the risk of corrosion under humid conditions. An important issue is the failures due to electrolytic metal migration. This paper describes an investigation of the electrolytic migration of $\mathrm{Sn}-\mathrm{Pb}$ solder lines on PCBs in humid environments under applied potential conditions. Studies were carried out using two electrode potentiostatic polarization experiments and measuring the resulting current due to electrolytic migration. The surface morphology of the electrodes before and after migration testing was investigates using SEM and EDS. An in-service failure of a Ceramic Capacitor due to electrolytic migration in humid environments is also presented.
\end{abstract}

\section{Introduction}

Corrosion reliability is a serious issue today for electronic devices, components, and multimetallic layers on printed circuit boards (PCBs) due to factors such as miniaturization, change in manufacturing practices, and wide spread usage (1-9). Both industrial and consumer electronics sector experiences serious corrosion reliability problems. The results are reduced life span for their products and heavy economic loss due to failures. Economic loss is also incurred for the users due to plant down time, loss of functionality of the device, or sometime catastrophic failures. Although the exact worldwide cost of electronic corrosion is yet to be estimated due to the primitiveness and complexity of the problem, it is assumed that the economic loss due to this problem is significantly large.

Miniaturization of the devices and components is one of the key factors reducing corrosion reliability. Over the last 10 years, size of the electronic components and PCBs has been reduced by over $70 \%$. For flip chip ICs, miniaturization amounts to $\sim 90 \%$. The average distance between components on a PCB has reduced from hundreds of micrometers in the mid 90 'ties to $\sim 5 \mu \mathrm{m}$ today. The closer spacing increases the electric 
field $(E=V / d)$ between points, which makes easy for the corrosion cell formation during local condensation in humid environments.

Studies on the size of dew droplet formation on surfaces under varying conditions of temperature and humidity shows that the average size varies from $20-50 \mu \mathrm{m}$ at about $50 \%$ RH (10). Hence, smaller distance on PCBs makes it easy for the local electrochemical cell to form. A major departure from conventional corrosion situations is the incredibly small volume of the material (of the order pico-grams) loss can cause failures.

However, irrespective of the field of application, the corrosion problems experienced by the electronic systems can be generalized as due to the following key factors. These are miniaturization together with: (i) unfavorable material combinations, (ii) DC or AC electric field applied to the system in use, (iii) process related ionic residues on the PCB surface $(11,12,7-9)$, and (iv) application related factors such as high humidity, gases, aggressive ions, dust etc $(1,4,6-9)$. Presently the knowledge on electronic corrosion is extremely limited.

One of the common corrosion failure modes observed on PCBs is the electrolytic migration. The electrolytic migration is an electrochemical phenomenon involving metal dissolution at the anode and deposition at the cathode, which is controlled by the chemistry of the solution layer over the components and electric potential. The electrolyte contact needed for the process to occur, is often established by an adsorbed surface layer of water on the PCB surface. Charged dust particles, which are attracted to the surface, enhance the possibility of formation of water layer as they absorb moisture. Therefore, migration involves dissolution and deposition reactions and metal ion transfer induced by such factors as metal dissolution, diffusion and migration.

$$
\begin{aligned}
& \mathrm{M} \rightarrow \mathrm{M}^{\mathrm{n}+}+\mathrm{ne} \mathrm{e}^{-} \text {(Anode or positive electrode) } \\
& \mathrm{M}^{\mathrm{n}+}+\mathrm{ne}^{-} \rightarrow \mathrm{M} \text { (Cathode or negative electrode) }
\end{aligned}
$$

At the cathode, a part of the current will also be used for other cathodic reactions such as oxygen reduction or hydrogen evolution depending on the solution chemistry and potential. Formation of metal complexes, salts or oxides are other possible anode reactions. However, the important factor is the deposition of the metal at the cathode. Due to large resistance within the thin solution layer, significant current localization occurs at the electrode surface leading to preferential deposition and growth in the form of dendrites from cathode towards anode (as shown in Figure 1) eventually filling the electrode gap and short circuiting two parts of the components temporarily or permanently.

On a PCB, several metals are susceptible to electrolytic migration such as $\mathrm{Cu}, \mathrm{Ag}, \mathrm{Sn}$, and $\mathrm{Pb}$. The electric potential on the PCB together with humidity makes these metals susceptible to electrolytic migration. No detailed understanding of the electrolytic migration phenomena related to different components on a PCB is available today. 


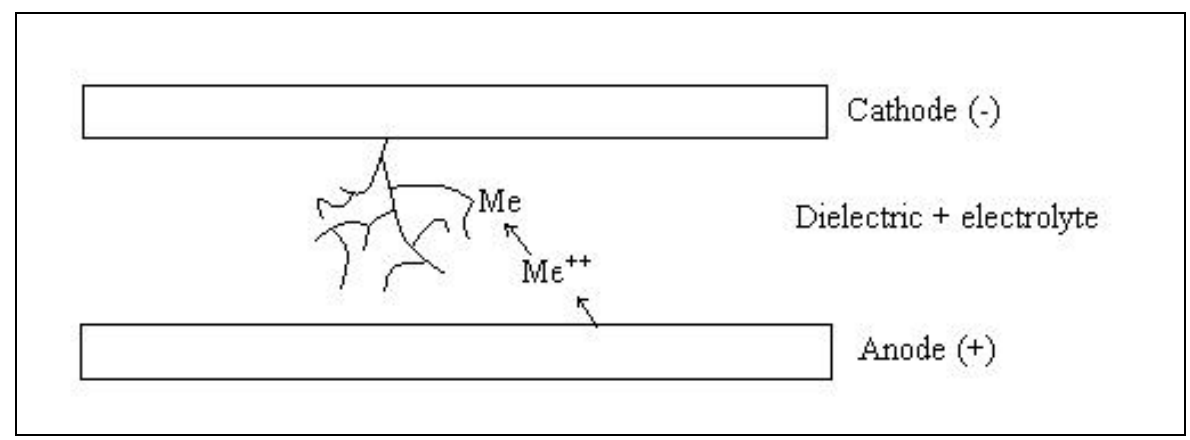

Figure 1. A schematic showing the electrolytic migration and dendrite growth between electrodes.

In this paper electrolytic migration of $\mathrm{Sn}-\mathrm{Pb}$ solder under humid conditions has been investigated using model $\mathrm{PCBs}$ with an array of $\mathrm{Sn}-\mathrm{Pb}$ solder lines. A two electrode potentiostatic polarization experiments with alternate lines of $\mathrm{Sn}-\mathrm{Pb}$ solder array as anode and cathode was employed for migration studies. The exposure environment was a humidity chamber with $100 \% \mathrm{RH}$. The resulting current spectrum was recorded as well as surface morphology investigation using Optical microscopy, SEM, and EDS. An inservice electrolytic migration failure of a ceramic chip capacitor on a PCB was also discussed to show how such failures occur in practice.

\section{Materials and Methods}

A model PCB with arrays of $\mathrm{Sn}-\mathrm{Pb}$ alloy conduction lines as shown Figure $2 \mathrm{a}$ was made by re-flow soldering process. Each set of array electrodes on the PCB (Figure 2a) has different separation distance between alternative lines. For the experiment, a suitable array electrode set was cut from the PCB. Figure $2 b$ shows a schematic of the cell set up arrangement for the electrolytic migration experiments. The array electrodes with cell connections as shown in Figure $2 b$ is placed inside a humidity chamber under saturated conditions. The electrodes were cleaned thoroughly prior to each experiment with alcohol followed by water to remove any unwanted organic or inorganic contaminants on the surface. The variables related to array electrodes for investigation was only the separation distance between electrodes, which was varied between $0.3 \mathrm{~mm}-3 \mathrm{~mm}$. Exposure condition variables are temperature and applied voltage. The applied voltage shown in this paper is the potential difference between the adjacent electrodes in the array, which means that each electrode is polarized to a value that is half of the applied potential to negative and positive side. The current resulting from the migration is recorded as a function of time until a permanent surge in current was observed due to dendrites (due to electrolytic migration as explained before) filling the gap, which leads to a permanent electrical short.

At the end of the experiments, the array electrodes were disconnected from the set up. They were observed using a Scanning Electron Microscope (SEM JEOL 5900) to elucidate dendrite morphology and EDS system (Oxford, Link ISIS) attached with SEM for chemical composition analysis. Microstructural analysis of the array electrode was also carried out using optical microscopy and SEM prior to migration experiments. 

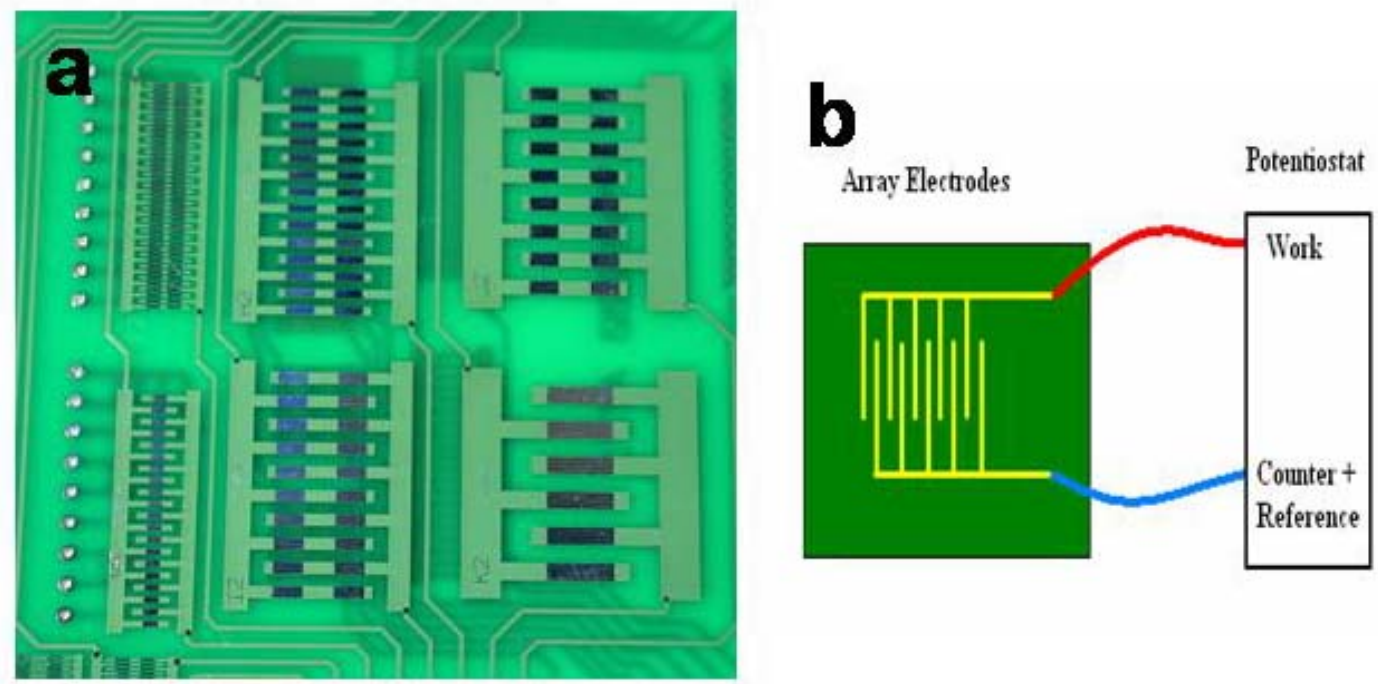

Figure 2. Electrodes and cell arrangement: (a) Model PCB with different electrode arrays and (b) cell arrangement used for the investigation with one set of arrays.

The in-service failure case reported in this paper is a ceramic chip capacitor failure from a PCB failed due to electrolytic migration under exposure to humid conditions and applied potential. The failure is caused by a humidity level above $60 \% \mathrm{RH}$ and potential values of the order $20 \mathrm{~V}$ DC.

\section{Results and Discussion}

\section{$\underline{\text { Surface topography and microstructure of array electrodes }}$}

Figure 3a shows an optical micrograph of a pair of electrode from the model PCB (Figure 2a). The electrodes are compact without any visual defects. A number of such layers were analyzed with different separation distance using optical microscope. No significant variation in separation distance was observed between different arrays. The surface topography of the re-flow solder layer was also found to be uniform with a smooth surface appearance. Figure $3 \mathrm{~b}$ shows the typical microstructure of the solder lines using $\mathrm{SEM}$. At high magnification the solder arrays showed a dendrite structure with $\mathrm{Pb}$ dendrites in Sn matrix. This is attributed to the solidification process of the solder alloy with eutectic composition. The phase with bright contrast is lead rich and the other has more Tin. Table 1 shows composition of the overall alloy and various phases marked in Figure 3b. Overall composition of the solder material is shown in spectrum 6, which consists of 59 wt. $\% \mathrm{Zn}, 32 \mathrm{wt} \% \mathrm{~Pb}$, and $9 \mathrm{wt} . \% \mathrm{Cu}$. The presence of copper is because of the higher interaction volume of the electron beam that will penetrate down to the base copper layer on the PCB over which the solder lines are formed by re-flow process. 

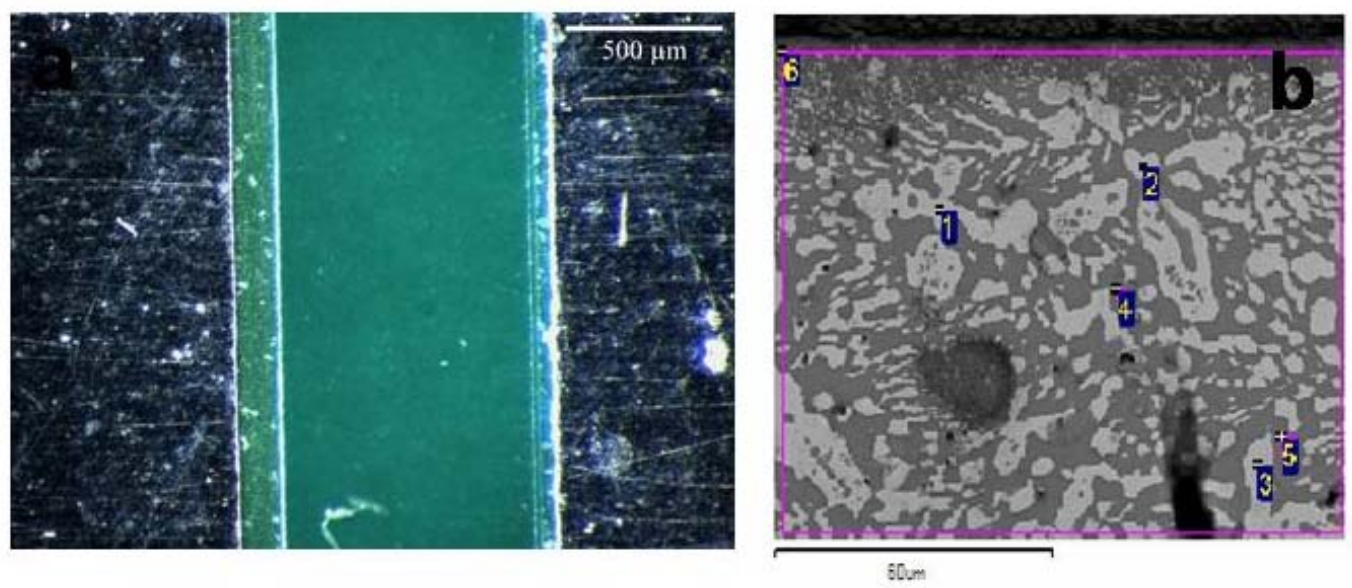

Figure 3. (a) Surface morphology of array electrodes, and (b) Microstructure of the array electrode at high magnification.

Table I: EDS analysis of array electrodes (Analysis areas are numbered in Figure $3 \mathrm{~b}$ )

\begin{tabular}{cccc}
\hline \multirow{2}{*}{ Analysis number } & \multicolumn{3}{c}{ Elements (wt. \%) } \\
\cline { 2 - 4 } & $\mathbf{C u}$ & Sn & Pb \\
\hline 1 & 3.58 & 3.60 & 92.82 \\
2 & 5.86 & 3.59 & 90.54 \\
3 & 2.93 & 3.19 & 93.88 \\
4 & 1.54 & 97.05 & 1.41 \\
5 & 1.54 & 92.34 & 6.12 \\
6 & 8.98 & 58.88 & 32.14 \\
\hline
\end{tabular}

\section{Current spectra from Electrolytic Migration experiments}

Figure 4 shows the current spectra resulting from the exposure of electrode arrays with varying separation distance (the distance between two oppositely charged lines on the array in Figure 2) under exposure to saturated humidity with an applied potential of $1 \mathrm{~V}$ at $50^{\circ} \mathrm{C}$. The resulting base current (marked in the figure) level for each curve is a function of the electric field acting between lines. The magnitude of electric field is controlled by the distance of separation, IR drop with in the solution layer, and the rate of faradic reactions occurring at the anode and cathode. The intermittent peaks (marked as temporary shorts) are due to dendrite formation and burning off, and a gradual increase in current to higher values (for example for the curve $0.3 \mathrm{~mm}$ distance after $20 \mathrm{~h}$ ) is due to a permanent short by dendrites filling the electrode gap. 


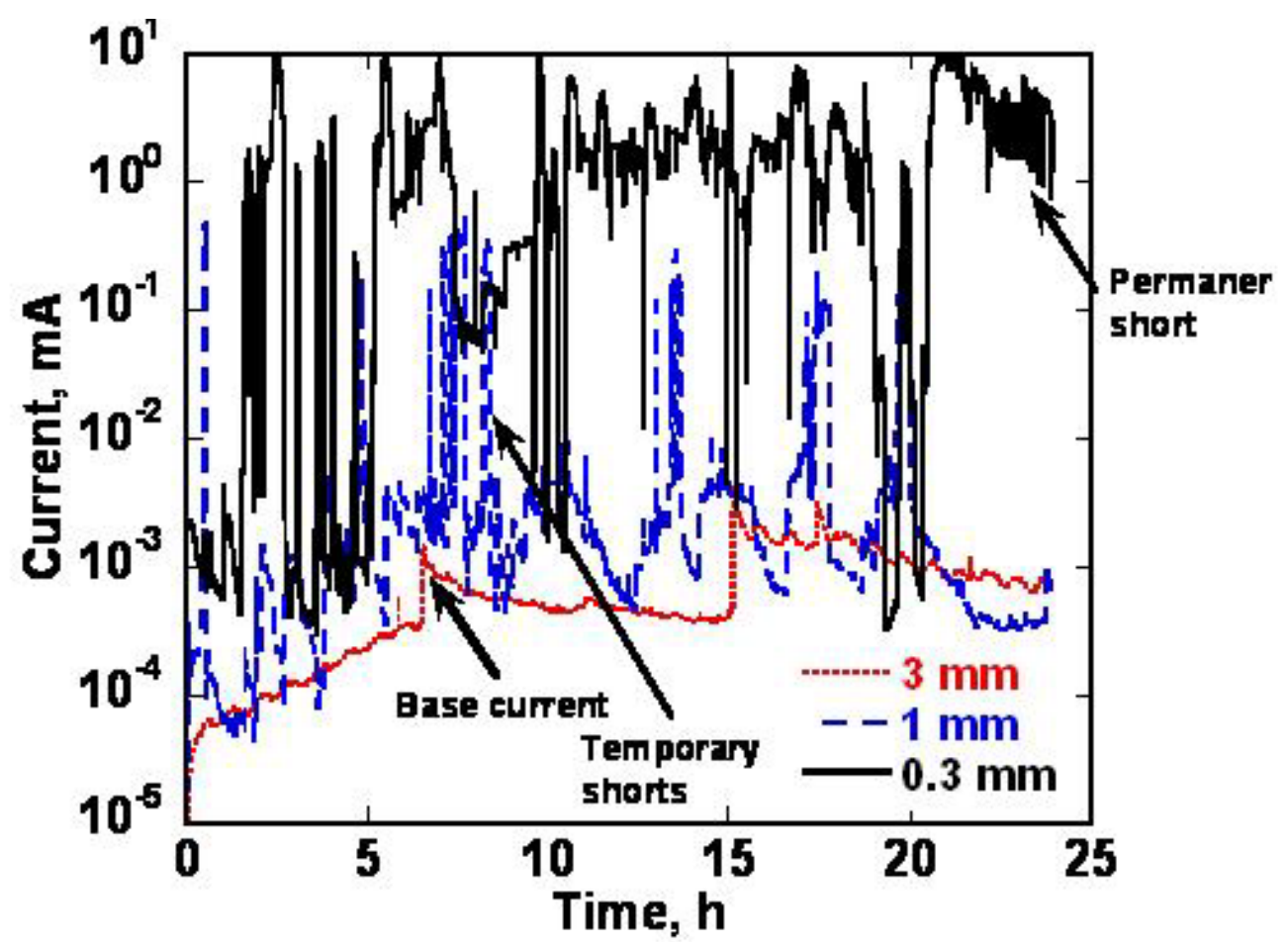

Figure 4. Migration current spectra as a function of separation distance.

The base current levels in Figure 4 (in electronic reliability terms, it is usually called as leakage current as it represents the level of current leaking through the solution layer between two points on a PCB surface) increases slightly with decrease in distance. This might be attributed to the increased electric field with decrease in separation distance. The difference in leakage current was high initially between various separation distances (by an order of magnitude), however, the difference decreases with exposure time. This is because with time as the ions build up in the solution due to dissolution of electrodes, naturally the current increases due to increased conductivity of the media reducing the difference between different separation distances. Table 2 gives the calculated electric filed between the conduction lines at various potential differences.

Table 2. Calculated electric filed between various separation distances

\begin{tabular}{cccc}
\hline Applied potential & \multicolumn{3}{c}{ Distance between electrodes and electric field strength } \\
\cline { 2 - 4 } difference $(\mathrm{V})$ & $0.3 \mathrm{~mm}$ & $1 \mathrm{~mm}$ & $3 \mathrm{~mm}$ \\
\hline 0.5 & $1.67 \mathrm{~V} / \mathrm{mm}$ & $0.50 \mathrm{~V} / \mathrm{mm}$ & $0.17 \mathrm{~V} / \mathrm{mm}$ \\
1.0 & $3.33 \mathrm{~V} / \mathrm{mm}$ & $1.00 \mathrm{~V} / \mathrm{mm}$ & $0.33 \mathrm{~V} / \mathrm{mm}$ \\
4.0 & $13.33 \mathrm{~V} / \mathrm{mm}$ & $4.00 \mathrm{~V} / \mathrm{mm}$ & $1.33 \mathrm{~V} / \mathrm{mm}$ \\
\hline
\end{tabular}

The curves in Figure 4 also shows intermittent peaks (temporary shorts) corresponding to instantaneous surge in current. The temporary electric shorts produced by a growing dendrite, which eventually burn off due to current surge during the shorting, produce these peaks. This process will continue until a significant volume of the dendrite is formed, which cannot be burned by the surge in current. The curve shows that the distance between electrodes has a significant effect on the temporary shorts as it can be observed that the number of peaks increases with decrease in distance between electrodes. The time elapsed until the formation of the first temporary short is also decreased with 
decrease in distance of separation. Also for $0.3 \mathrm{~mm}$ distance, a permanent short has been established after $20 \mathrm{~h}$ of exposure that is absent for other distances. Takemoto (13) also reported a decrease in the time required for the formation of first short with reduction in distance between conductors, as the metal ions in this case have to migrate only shorter distances under higher electric filed. From the perspective of the miniaturization of the electronic devices, the present results clearly show how a decrease in distance on PCB could influence electrolytic migration and therefore cumulative damage and malfunction of the components due to temporary shorts and current surge.

Figure 5 shows the current spectrum from a similar experiment using $0.3 \mathrm{~mm}$ wide electrode array at $30^{\circ} \mathrm{C}$ with different potential values between them. The base leakage current increases by an order of magnitude with increase in potential from $0.5 \mathrm{~V}$ to $1 \mathrm{~V}$, while further increase in potential did not show any increase. At $0.5 \mathrm{~V}$, no temporary shorts were observed showing that the potential is not enough for electrolytic migration under these conditions. However, increasing the voltage to higher values showed temporary peaks $(\sim 1.5 \mathrm{~h}$ for $1 \mathrm{~V}$ and $\sim 9 \mathrm{~h}$ for $4 \mathrm{~V})$ and incidentally for $1 \mathrm{~V}$, a permanent short was observed after $18 \mathrm{~h}$ of exposure. The number of temporary shorts were slightly more for the $4 \mathrm{~V}$, however, the width of the peaks are higher for $1 \mathrm{~V}$. At 1 volt, the peaks (dendrites) typically have duration of $1 \mathrm{~h}$, where as at $4 \mathrm{~V}$ they burn off immediately. This is understandable as more migration is expected at higher potential and therefore growth of dendrites. Formation of more dendrites gives rise to more temporary shorts, while width of the peak decreases with increase in voltage due to fast burning of the formed dendrites due to higher current levels. Takemoto (13) has observed similar behaviour for $\mathrm{Sn}-\mathrm{Pb}$ electrode with increasing potential gradient between them. The increased potential gradient enhances the driving force of migration of the metal ions, as well as it enhances the dissolution of metal ions, until the limiting corrosion current density is reached.

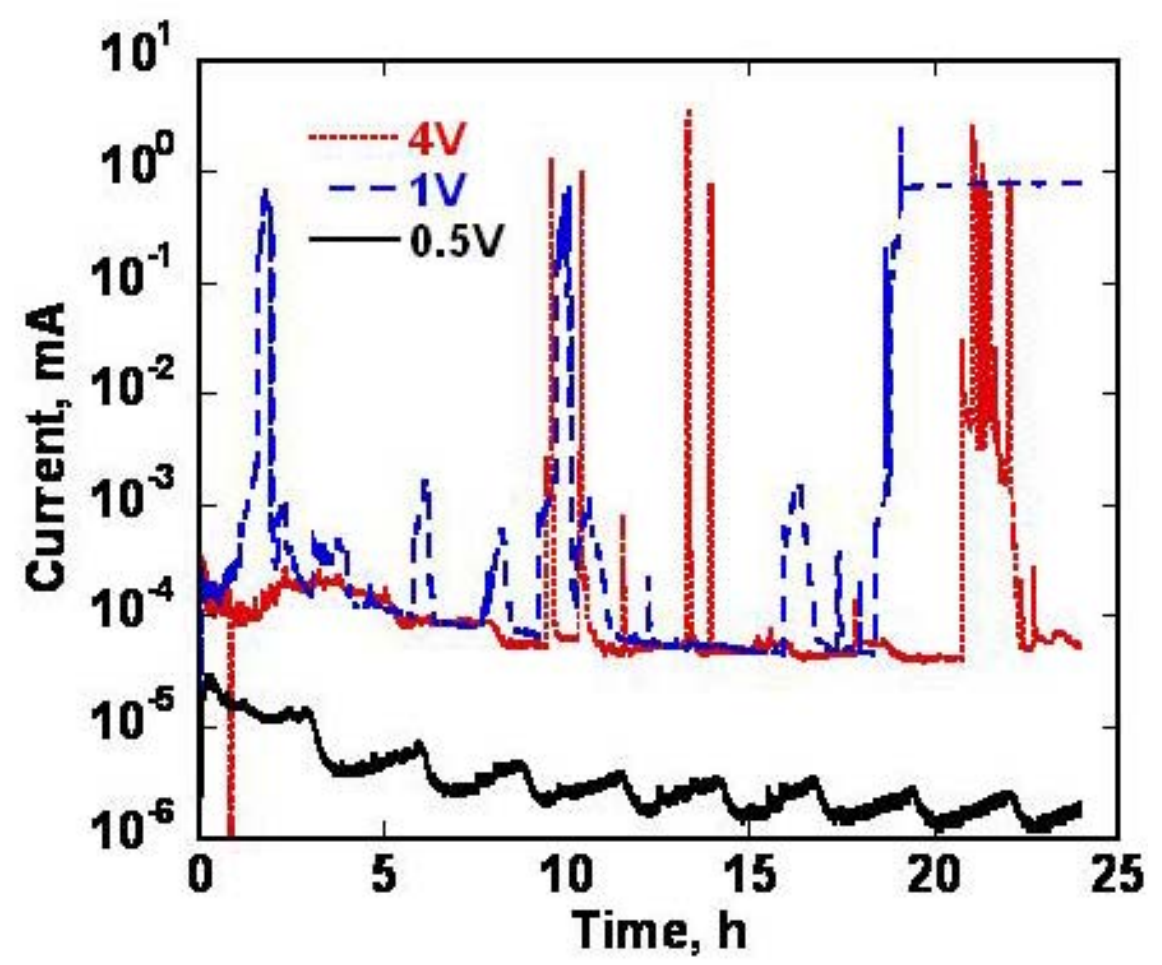

Figure 5. Migration current spectra as a function of applied potential. 
Figure 6 shows the migration current spectrum as a function of temperature from an electrode array with $0.3 \mathrm{~mm}$ width with $4 \mathrm{~V}$ potential difference. The effect of temperature is clear as the base current level at $30^{\circ} \mathrm{C}$ is low and only few temporary shorts are observed starting after $9 \mathrm{~h}$. On the other hand at $40^{\circ} \mathrm{C}$ after $4 \mathrm{~h}$ and $50^{\circ} \mathrm{C}$ within few minutes, current increases to a value of $1 \mathrm{~mA}$ corresponding to permanent short due to electrolytic migration. The observed effects are assumed to be due to increased rate of the overall processes including transport through the solution as the temperature increases. The results are very relevant as in practice PCBs undergo temperature cycling to the tune of $20-30^{\circ} \mathrm{C}$ or more depending on the application. A localized variation in temperature is also possible between different locations on a PCB surface.

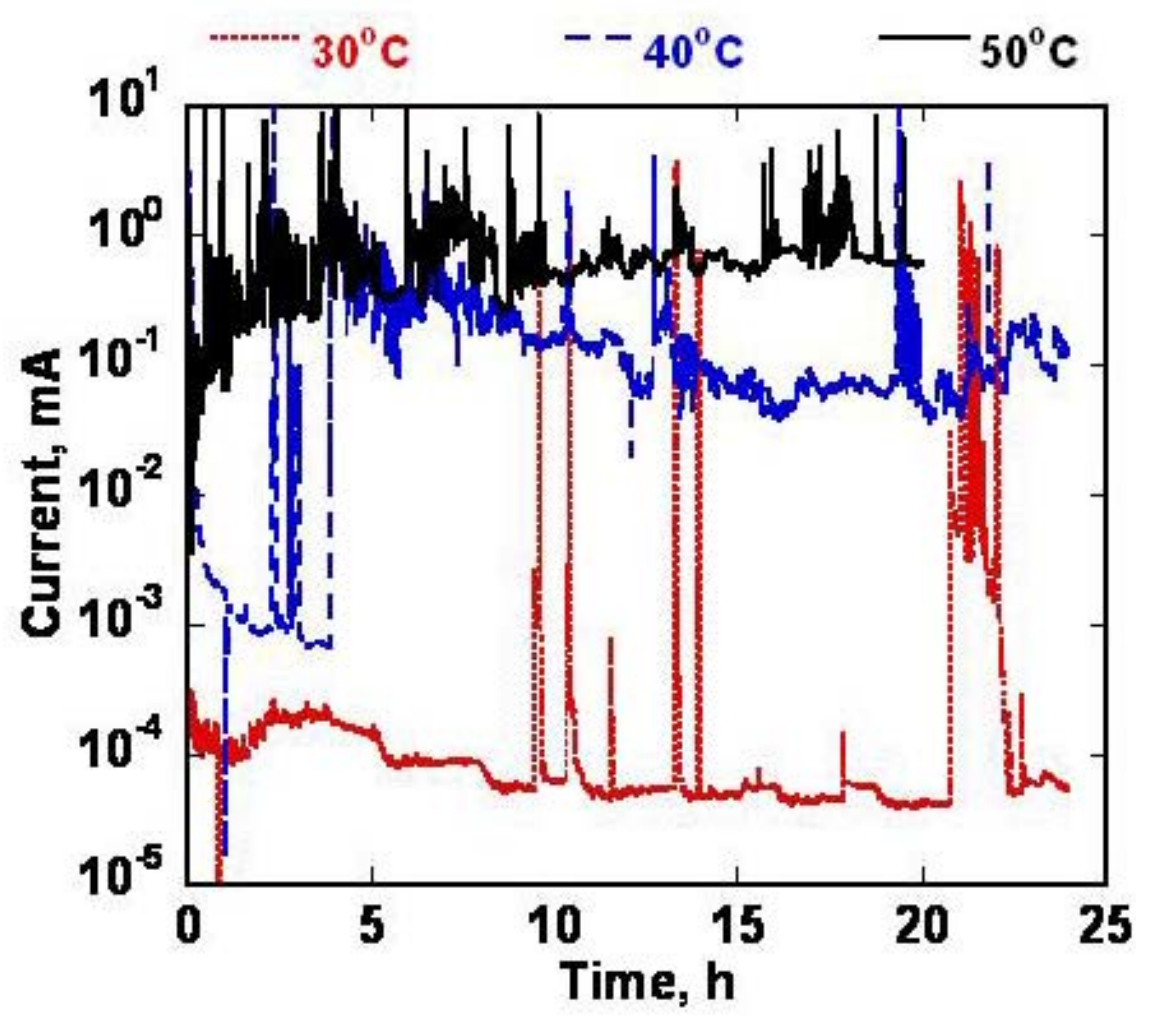

Figure 6. Migration current spectra as a function of exposure temperature.

\section{Surface morphology of exposed array electrodes}

Figure 7 shows the optical micrographs of the electrodes after migration experiments. Localized growth of dendrite could be seen (see arrows in Figure 7a) and white patches representative of the heat damage on the epoxy polymer. This is more visible in Figure $7 \mathrm{~b}$ where the heat damage to the polymer is clearly seen as white patches together with dendrites covering one of the electrode surfaces. The heat damage indicates that when two conductors are short-circuited, some amount of heat is generated depending on the level of current. The amount of dendrites as well as the extent of damage to the polymer due to heat was found to be largest on the PCBs exposed to highest potential difference. Also, the electrode systems separated by the smallest distance were more affected by this heat damage than the electrode systems with larger distances. 

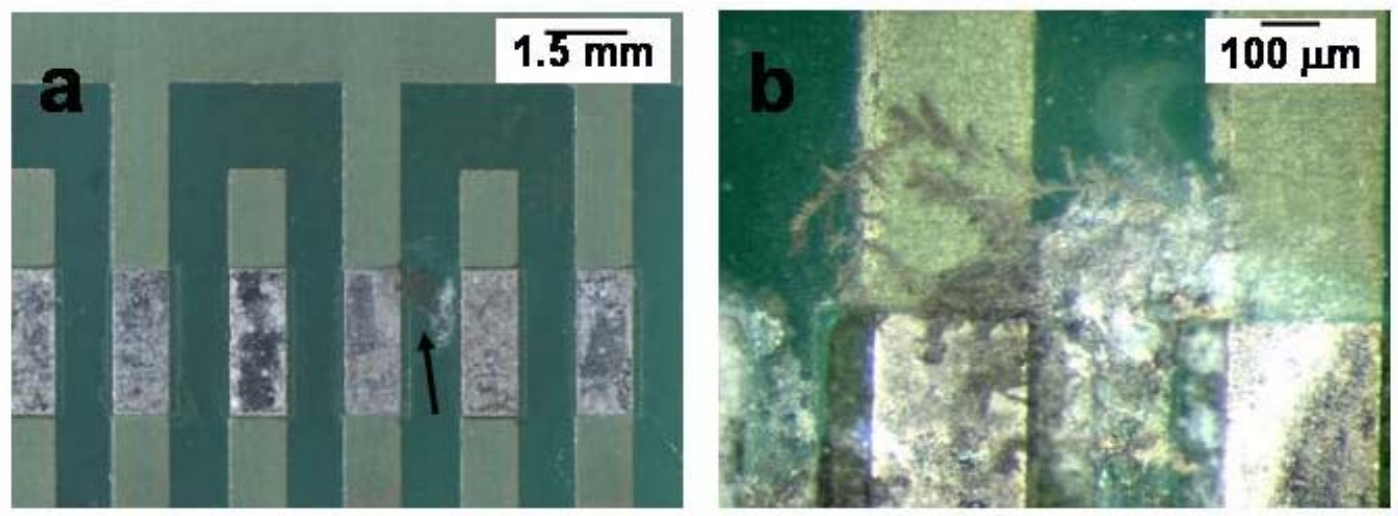

Figure 7. Optical micrographs showing morphology of electrode arrays $(1 \mathrm{~mm}$ width, $\left.40^{\circ} \mathrm{C}, 4 \mathrm{~V}\right)$ after migration experiments.

Figure 8 shows the SEM image of the array electrodes exposed at $50^{\circ} \mathrm{C}$ at $4 \mathrm{~V}$ after migration experiments. The morphology of the migrated species between electrodes showed two types of morphology: (i) slim fine branched dendrites consisting mainly $\mathrm{Sn}$ ( $\sim 80-90 \%$, marked 1$)$ and (ii) bulky dendrites consisting mainly $\mathrm{Pb}(\sim 50-80 \%$, marked 2$)$ with some $\mathrm{Sn}$. Formation of $\mathrm{Sn}$ rich dendrites with similar appearance for $\mathrm{Sn}-\mathrm{Pb}$ alloy was reported by $\mathrm{Yu}$ et al $(14,15)$. Formation of Sn rich dendrites was more dependent on the applied potential difference. The amount of Sn rich dendrites increased with increase in applied potential.

Investigation by $\mathrm{Yu}$ et al. $(14,15)$ found that the morphology of the dendrite formation is dependent on the alloy composition. For Sn-37 Pb and Sn-36 Pb-2 Ag alloys at 5V under exposure to $75 \% \mathrm{RH}$ at $85^{\circ} \mathrm{C}$ for $50-300 \mathrm{~h}, \mathrm{~Pb}$ was the main migrating element and the dendrite formed was long needle-shaped $(14,15)$. Overall chemical analysis in the present investigation also showed that the main migrating species was $\mathrm{Pb}$. However, none of the fine $\mathrm{Pb}$ dendrites reported by $\mathrm{Yu}$ et al. $(14,15)$ was found in the present investigation. Dendrites with $\mathrm{Pb}$ and $\mathrm{Sn}$ found in the present study was very much bulkier than reported by $\mathrm{Yu}$ et al. $(14,15)$ and they did not constitute pure $\mathrm{Pb}$, but a mixture of $\mathrm{Pb}$ and $\mathrm{Sn}$. However, a comparison of the dendrite morphology in the present study with the Pourbaix diagram constructed for $\mathrm{Pb}$ in water (Figure 9) clearly shows that at $\mathrm{pH}$ values between 6-11 there is large area where $\mathrm{PbOH}^{+}$is a stable species. As the charged species $\mathrm{PbOH}^{+}$is formed, this is believed to migrate under the electric field to the cathode and absorb on the surface. An experiment using Quartz Crystal Microbalance (QCM) coupled to a $\mathrm{Pb}$ electrode with $\mathrm{QCM}$ electrode as cathode at potential differences with in the region of the $\mathrm{PbOH}^{+}$stability showed formation of deposited products with similar morphology as in Figure 7a on the QCM electrode surface. An EDS analysis of the QCM deposits indicated that they consist of lead hydroxide type of species. The atomic ratio of $\mathrm{Pb} / \mathrm{O}$ was found to be approximately $40 / 60$. However, more investigation as a function of potential, $\mathrm{pH}$ and alloy composition is necessary to confirm what kind species is forming and migrating in detail. 

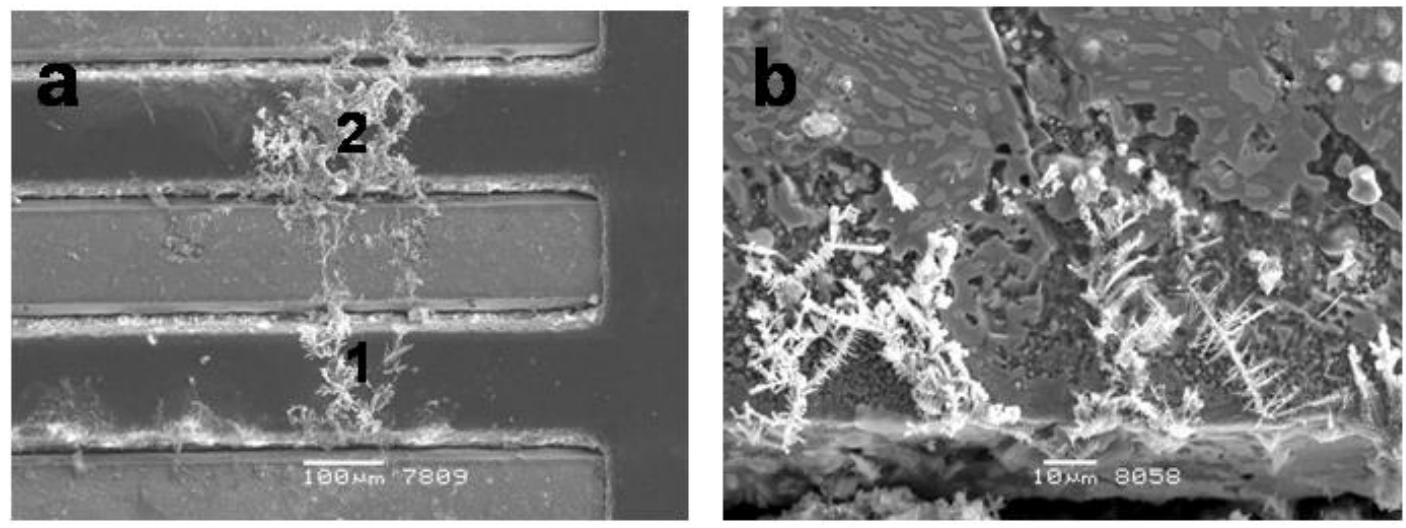

Figure 8. SEM pictures of migration tested electrode array at $50^{\circ} \mathrm{C}, 4 \mathrm{~V}$ : (a) dendrite morphology, and (b) selective dissolution of microstructural features.

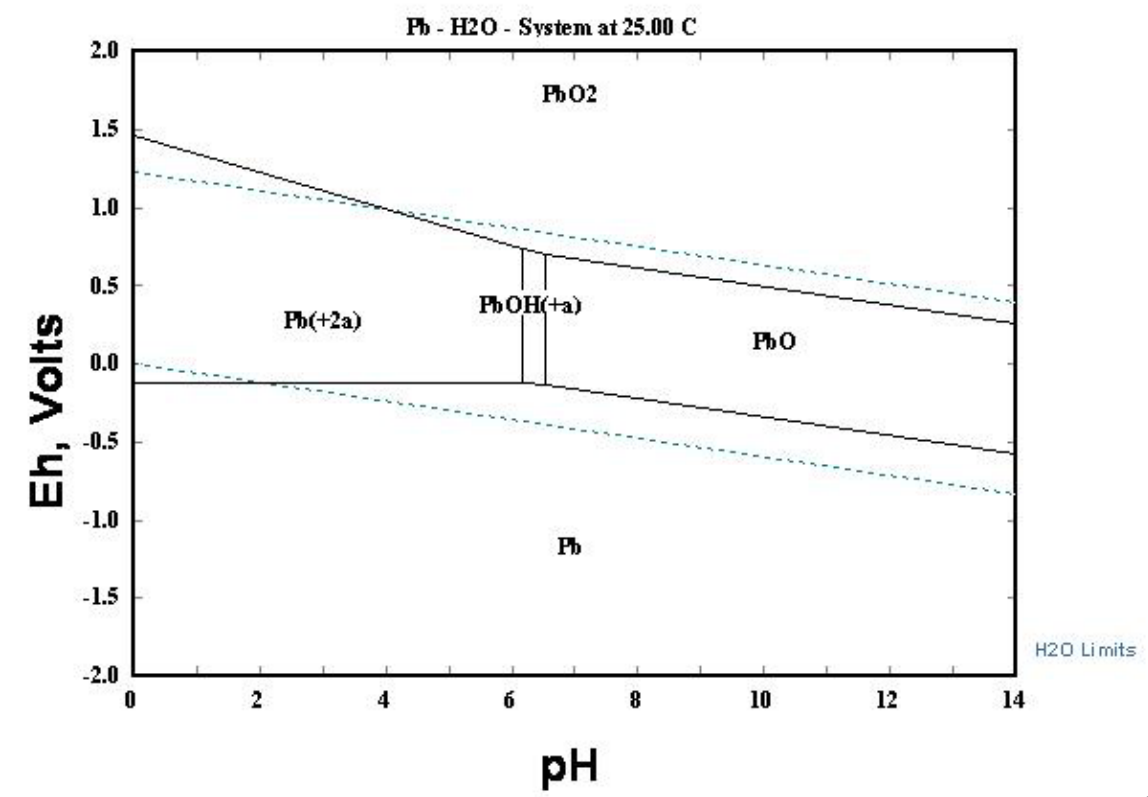

Figure 9. Pourbaix diagram for $\mathrm{Pb}$ in pure water with Molarity of $\mathrm{Pb}$ ions $1 \times 10^{-6} \mathrm{Mols} / 1$ constructed using standard Outokumpu HSC Chemistry 4.0 software.

At higher magnification, the effect of microstructure on dissolution is observed as shown in Figure $8 b$. The bright areas corresponding to $\mathrm{Pb}$ rich phase is preferentially dissolved compared to the Sn rich phase. This is understandable as $\mathrm{Sn}$ is more passive and less active than $\mathrm{Pb}$.

Figure 10 clearly shows the edge effect on the electrolytic migration. As the current lines concentrate

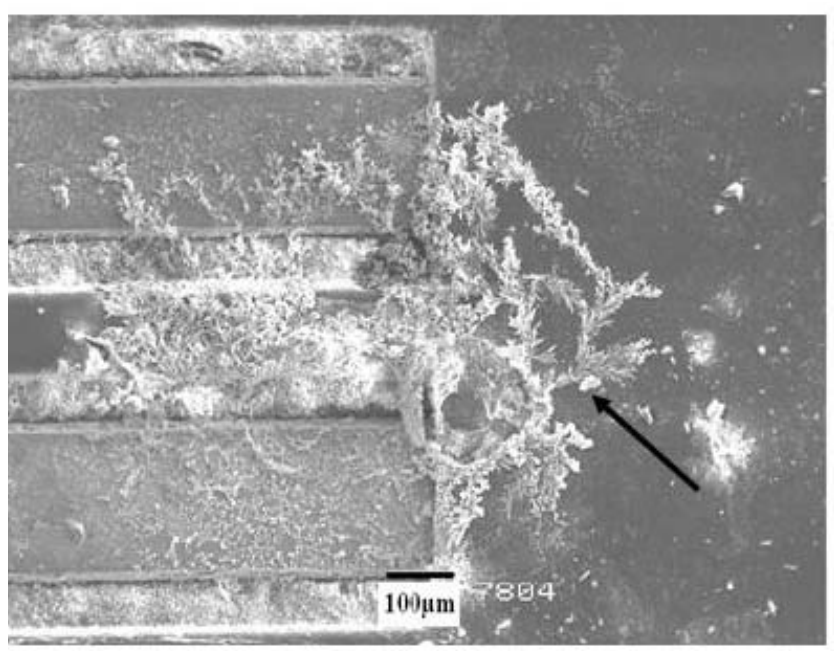

Figure 10. Edge effect on electrolytic migration. 
preferentially at the sharp edges, preferential growth of dendrites in the form of an arc could be seen at the edge of the electrodes (see arrow in Figure 10).

\section{$\underline{\text { In-service failure of a Ceramic Capacitor due to EM }}$}

As the electronic industry moves towards using higher density circuit board assemblies, the size of the ceramic capacitors and resistors are decreasing rapidly. The decreasing size together with presence of migration susceptible material in the construction of chip capacitors makes them susceptible to electrolytic migration failures under exposure to humid conditions.

Figure 11 shows a typical example of such in-service failure of a ceramic capacitor on a PCB under humid conditions. This ceramic capacitor had a Sn termination electrode that wave soldered on to the $\mathrm{PCB}$ using $\mathrm{Sn}-\mathrm{Pb}$ alloy. The ceramic was dielectric Barium Titanate. A number of ceramic capacitors on this PCB have failed due to electrolytic migration in-service. The capacitor shown in Figure 11 shows migration tracks from cathode to anode produced by electrolytic migration. The capacitor has also been broken up at the centre possibly due to penetration of humidity inside and downward migration as shown in the schematic in Figure 11.

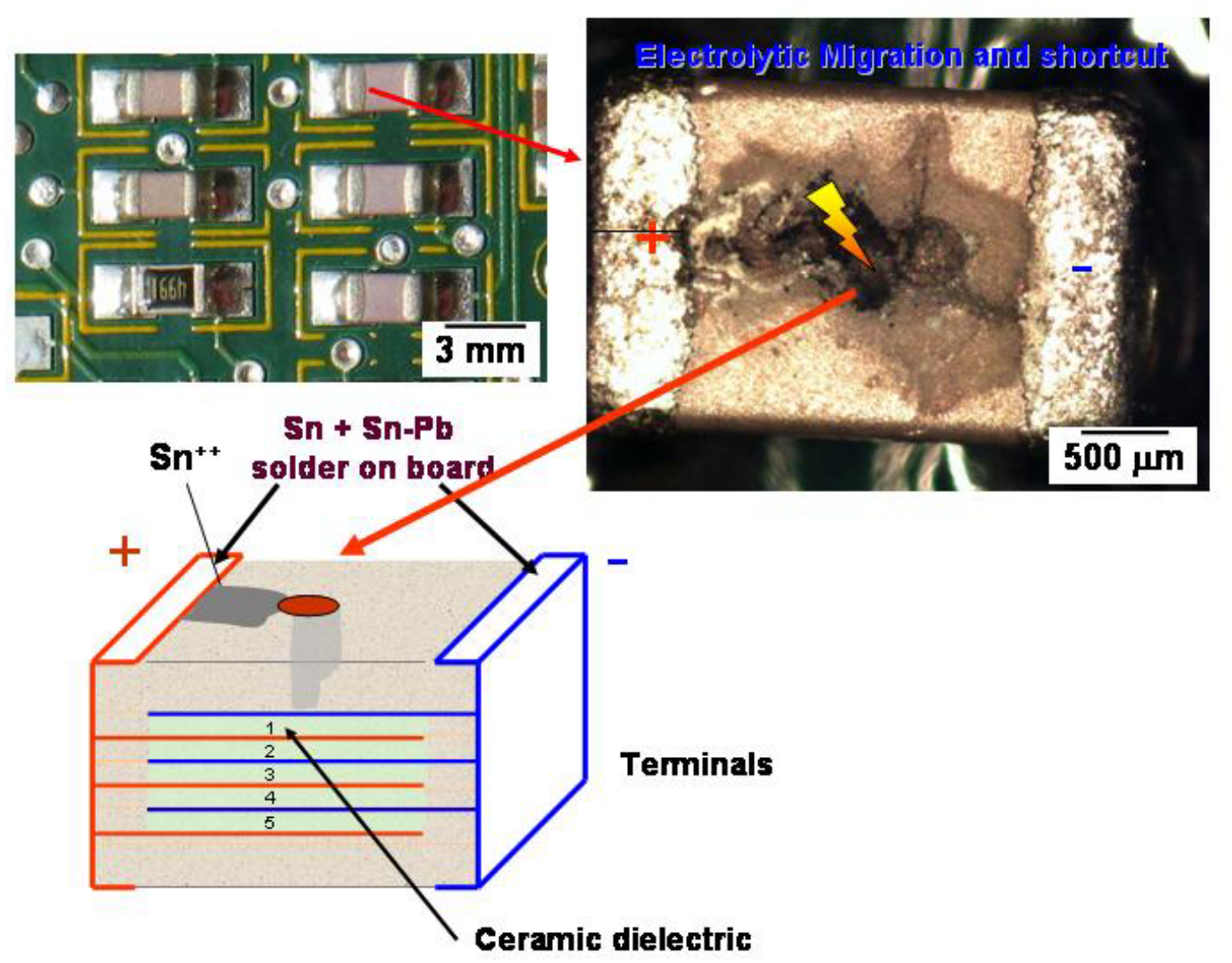

Figure 11. An in-service electrolytic migration failure of a ceramic capacitor.

The ingress of water into the capacitor leads to evolution of gases at the negatively biased metal foils of the capacitor as well as downward migration causing shorting and current surge. Microscopic flaws in the ceramic layer lead to ingress of water for facilitating a conducting path between the inner electrode layers of the capacitor to the outer electrodes 
(as shown in the schematic). This results in electrochemical reactions at the inner foils depending on the bias. A possible scenario is the coupling of the cathode foil layers with positive electrode of the capacitor giving rise to cathodic reactions on the inside foils evolving gases making the capacitor to break.

\section{Conclusions}

1. Electrolytic migration of $\mathrm{Sn}-\mathrm{Pb}$ solder arrays in humid environments created temporary shorts and permanent shorts between conductors. The frequency, intensity of shorts, and time required for permanent short was found to be a function of electrode spacing, potential bias, and temperature.

2. Two types of dendrite morphology have been found: (i) fine branched dendrites that are $\mathrm{Sn}$ rich, and (ii) bulky dendrites that consist of either $\mathrm{Pb}$ alone or a mixture of $\mathrm{Pb}$ and Sn. The amount of fine dendrites was a function of the potential bias.

3. In-service failure of a PCB showed migration and cracking on a ceramic capacitor due to surface migration and migration downward possibly due to defects in the ceramic layer.

\section{References}

1. R.Ambat and P.Møller, Corrosion Sci., 49, 2866 (2007).

2. C.W. Nielsen, A.A. Rasmussen, R. Ambat, and P. Møller, Proc. of the International Conference on Electronic Packaging, Japan, April 19-21 (2006).

3. C.W. Nielsen, R. Ambat, A.A. Rasmussen, and P. Møller, Proc. of Pan Pacific Microelectronic Symposium, USA, January (2006).

4. R. Ambat and P. Møller, Proceedings of Korrosion- mekanismer, havarier, beskyttelse, p. 161, DMS Vintermødebog (2005).

5. A.A. Rasmussen, R. Ambat, and P. Møller, "Corrosion possibilities in Dome/Dome pad systems used at Nokia" Report to Nokia, 20 pages (2005).

6. H. Risto, R. Lahtinen, Reima, Corrosion and climatic effects in electronics, published by VTT Automation, Finland (2000).

7. R. Lahtinen, R. Heinonen, Electrochemical Society Proceedings, 99-29, 155 (1999).

8. G. Di Giacomo, Reliability of electronic packages and semiconductor devices, McGarw-Hill, USA (1996).

9. M. Yunovich, Appendix Z www.corrosioncost.com/pdf/electronics.pdf

10. S. Matsumoto, Meas. Sci. Technol. 14, 2075 (2003).

11. T. Munson, Process control and qualification of cleanliness issues, www.residues.com (2006).

12. T. Munson, The failure of a circuit: Reliability effects of process residues, www.residues.com (2006).

13. T. Takemoto, R.M. Latanision, T.W. Eagar, A. Matsunawa, Corrosion Sci., 39, 1415 (1997).

14. D.Q. Yu, W. Jillek, E. Schmitt, J. Mat. Sci., 17, 219 (2006).

15. D.Q. Yu, W. Jillek, E. Schmitt, J. Mat. Sci., 17, 229 (200). 